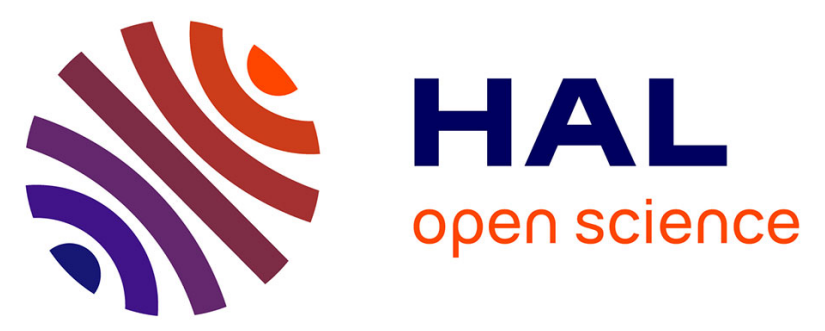

\title{
A Journey in Lanthanide Coordination Chemistry: From Evaporable Dimers to Magnetic Materials and Luminescent Devices
}

Kevin Bernot, Carole Daiguebonne, Guillaume Calvez, Yan Suffren, Olivier Guillou

\section{To cite this version:}

Kevin Bernot, Carole Daiguebonne, Guillaume Calvez, Yan Suffren, Olivier Guillou. A Journey in Lanthanide Coordination Chemistry: From Evaporable Dimers to Magnetic Materials and Luminescent Devices. Accounts of Chemical Research, 2021, 54 (2), pp.427-440. 10.1021/acs.accounts.0c00684 . hal-03128529

\section{HAL Id: hal-03128529 \\ https://hal.science/hal-03128529}

Submitted on 22 Feb 2021

HAL is a multi-disciplinary open access archive for the deposit and dissemination of scientific research documents, whether they are published or not. The documents may come from teaching and research institutions in France or abroad, or from public or private research centers.
L'archive ouverte pluridisciplinaire $\mathbf{H A L}$, est destinée au dépôt et à la diffusion de documents scientifiques de niveau recherche, publiés ou non, émanant des établissements d'enseignement et de recherche français ou étrangers, des laboratoires publics ou privés. 


\section{A journey in lanthanide coordination chemistry:}

\section{from evaporable dimers to magnetic materials and}

\section{luminescent devices}

Kevin Bernot*, Carole Daiguebonne, Guillaume Calvez, Yan Suffren and Olivier Guillou

Univ Rennes, INSA Rennes, CNRS, ISCR (Institut des Sciences Chimiques de Rennes), UMR

6226; 35000 Rennes (France)

CONSPECTUS. Lanthanide ions are prime ingredients for the design of compounds, materials and devices with unique magnetic and optical properties. Accordingly, coordination chemistry is one of the best tool to build molecular edifices from these ions because it allows a careful control of the ions environment and of the dimensionality of the final compound.

In this Account, we review our results on lanthanide-based dimers. We show how a pure fundamental study on lanthanide coordination chemistry allow investigating a full continuum of results from compound, to material and then devices. The conversion of molecules into materials is a tricky task because it requires a strong molecular robustness toward the surface deposition processes as well as a preservation and detectability of the molecules properties in the material. Additionally, the passage of a material toward a device implies a material with a given function, for example a tailored response to an external stimulus. 
To do so, we targeted neutral and isolated molecules whose transfer on surfaces by chemi- or physi-sorption is much easier than that of charged molecules or extended coordination networks. Then, we focused on molecules with very strong evaporability to avoid wet chemistry deposition processes that are more likely to damage the molecules and/or to distort their geometries.

We thus designed lanthanide dimers based on fluorinated $\beta$-diketonates and pyridine- $N$-oxide ligands. As expected, they show remarkable evaporability but also strong luminescence and interesting magnetic behavior as they behave as Single-Molecule Magnet (SMM). Ligands substitutions and stoichiometric modifications allow optimizing the geometric organization of the dimers in the crystal packing as well as their evaporability, SMM behavior, luminescent properties or their ability to be anchored on surfaces. Most of all, this family of molecules show a strong ability to form thick films on various substrate. This allows converting these molecules into magnetic materials and luminescent devices.

Magnetic materials can be designed by creating thick films of the dimers deposited on gold. These films have been designed and investigated with the most advanced techniques of on-surface imaging (Atomic Force Microscopy, AFM), on-surface physico-chemical characterization (X-ray Photoelectron Spectroscopy (XPS), Time of Flight - Secondary Ion Mass Spectroscopy (TofSIMS)) and on-surface magnetic investigation (Low-Energy Muons Spin Relaxation (LE- $\mu$ SR)). Contrary to what was previously observed on other films of SMM, no depth-dependence of the SMM behavior was observed. This means that the dimers do not suffer from the vacuum or substrate interface and behave similarly, whatever their localization is. This exceptional magnetic robustness is a key ingredient for the creation of materials for molecular magnetic data storage. 
Luminescent devices can be obtained by layering molecular films of the dimers with copper-rich solid-state electrolyte between ITO/Pt electrodes. Electromigration of $\mathrm{Cu}^{2+}$ ions into the films of $\mathrm{Eu}^{3+}-, \mathrm{Tb}^{3+}$ - and $\mathrm{Dy}^{3+}$-dimers quench their luminescence. This luminescence tuning by electromigration is reversible and this setup can be considered as a proof-of-concept of full solid-state luminescent device where reversible coding can be tailored by an electric field. It is envisioned for optical data storage purposes. In the future, it could benefit also from the SMM properties of the molecules to pave the road toward multifunctional molecular data storage devices.

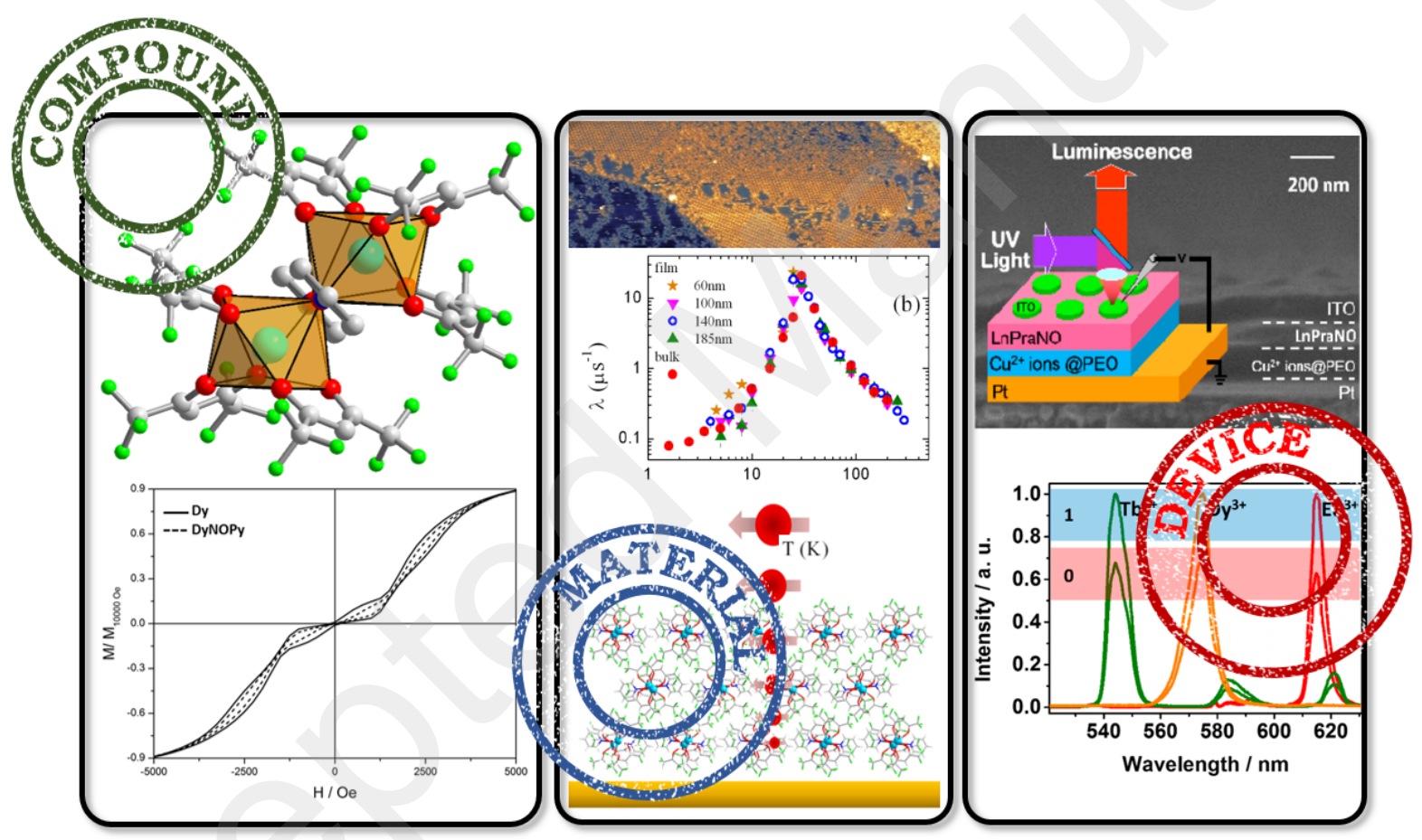


Key references:

Yi, X.; Bernot, K.; Pointillart, F.; Poneti, G.; Calvez, G.; Daiguebonne, C.; Guillou, O.; Sessoli, R.: A Luminescent and Sublimable Dy(III)-Based Single-Molecule Magnet. Chem.-Eur. J. 2012, $18,11379-11387$. This work is the seminal work on the dimer family that describe their singlemolecule magnet (SMM) behavior, luminescent and sublimation properties.

Huang, G.; Yi, X.; Jung, J.; Guillou, O.; Cador, O.; Pointillart, F.; Le Guennic, B.; Bernot, K.: Optimization of Magnetic Relaxation and Isotopic Enrichment in Dimeric Dy(III) SingleMolecule Magnets. Eur. J. Inorg. Chem. 2018, 326-332. This work reports the chemical strategies used for dimers optimization toward slow magnetic relaxation

Cimatti, I.; Yi, X.; Sessoli, R.; Puget, M.; Guennic, B. L.; Jung, J.; Guizouarn, T.; Magnani, A.; Bernot, K.; Mannini, M.: Chemical Tailoring of Single Molecule Magnet Behavior in Films of Dy(III) Dimers. Appl. Surf. Sci. 2018, 432, 7-14. This work reports the chemical strategies for dimers optimization toward films of slow relaxing molecules

Kiefl, E.; Mannini, M.; Bernot, K.; Yi, X.; Amato, A.; Leviant, T.; Magnani, A.; Prokscha, T.; Suter, A.; Sessoli, R.; Salman, Z.: Robust Magnetic Properties of a Sublimable Single-Molecule Magnet. ACS Nano 2016, 10, 5663-5669. This work is the key report on the observation of SMM behavior in films of dimers. The use of $\mu$-SR investigation demonstrates for the first time a robustness of the SMM properties whererever the muons are implanted from film top layers to substrate. Dimers are thus turned into an efficient magnetic material

Yi, X.; Shang, J.; Pan, L.; Tan, H.; Chen, B.; Liu, G.; Huang, G.; Bernot, K.; Guillou, O.; Li, R.W.: Reversible Luminescence Modulation Upon an Electric Field on a Full Solid-State Device Based on Lanthanide Dimers. ACS Appl. Mater. Interfaces 2016, 8, 15551-15556. This work show how the dimers can be turned into a luminescent device 


\section{1) Introduction}

Turning molecules ${ }^{1-3}$ into materials ${ }^{4}$ and then devices ${ }^{5}$ is a very challenging task. To do so, coordination chemistry ${ }^{6,7}$ is a very powerful tool because of its ability to synthesize functional or poly-functional molecules ${ }^{8}$ with controlled topologies. It allows elaborating and controlling the arrangement of metallic sites in a crystal packing as well as the dimensionality of a final compound. Remarkable examples of $0 \mathrm{D},{ }^{9,10} 1 \mathrm{D},{ }^{11,12} 2 \mathrm{D},{ }^{13,14}$ and $3 \mathrm{D}^{15,16}$ molecular architectures can be produced and in some cases efficiently turned into materials. Indeed, coordination chemistry is a powerful strategy because the chemical and geometrical properties of a compound can be anticipated and tuned to enable its conversion into a material and then a device. ${ }^{17}$

Coordination chemistry is particularly efficient with lanthanide ions because their appropriate association with organic ligands ${ }^{18-22}$ induces a specific ligand field ${ }^{23}$ that can reveal, tailor and optimize their physico-chemical properties. This is particularly true with single-molecule magnets $(\mathrm{SMM})^{24}$ and $4 \mathrm{f}-\mathrm{SMM}$ are clear examples of how a careful control of the electrostatic field around a magnetic ion is a key point to allow its efficient magnetic slow relaxation..$^{25,26}$

$\mathrm{Tb}^{\mathrm{III}}$ and Dy ${ }^{\mathrm{III}}$ are the most magnetically anisotropic lanthanides. This is why they are used to build $4 \mathrm{f}-\mathrm{SMM} .{ }^{27}$ These ions are trivalent and in most cases stable in eight-coordinated environment, even if greater and smaller coordination numbers can be found especially in organometallic species. ${ }^{28,29}$ Theoretical rationalizations on Dy-SMM showed that if monodentate anionic ligands are considered only two out of the five possible geometric arrangement around a given Dy ${ }^{\text {III }}$ provide efficient geometries for the observation of SMM relaxation. ${ }^{30}$ Accordingly, chemists tend to use polydentate anionic ligands that provide i) more adapted electrostatic arrangements for SMM relaxation ii) more stable complexes (entropic stabilization) iii) more predictable molecular geometry iv) less binding sites for solvent molecules that is, in most cases, 
water molecules because of the very high hydration enthalpies of the lanthanide ions. Except in some rare examples ${ }^{31}$ such water molecules make the rationalization of the SMM properties difficult ${ }^{32}$ and should be avoided.

Macrocyclic ligands (tetra-coordinating or more) can be used but often lead to charged species that are not always adapted for the conversion of molecules into materials. Accordingly, anionic bis- and tris-chelating ligands are preferred because they give rise preferentially to a neutral molecule with only two free and neutral binding sites for solvent molecules. Then, if ligand steric hindrance is limited, Lewis acidity maximized and an appropriate bridging ligand introduced, these molecules can react two-by-two to form a water-free neutral dimer.

Consequently, a huge amount of work is reported on dimeric $4 \mathrm{f}-\mathrm{SMM}^{31,33}$ because they combine the above mentioned straightforward synthesis with chemical stability and tunability. Chemical stability is an asset for material design because films or hybrid molecular magnetic structures are much easier to investigate on air- and moist-stable molecules than for example on high performance organometallic $\mathrm{SMM}^{29}$ that offer tremendous SMM performances but, to date, still limited stability. Chemical tunability is another asset because it allows modifying and understanding the factors that governs the magnetic properties but also the robustness toward a deposition process or the interaction with a substrate. Therefore, dimeric 4f-SMM became key targets of our investigations.

\section{2) The search of the appropriate molecule}

\section{a. The targeted compound: a lanthanide dimer ${ }^{1}$}

Accordingly, in order to obtain a device made of stable and robust films of SMM we targeted a dimeric molecule with several key assets: i) a molecule with favorable SMM properties, ii) easily 
sublimable $^{34-36}$ on surfaces ${ }^{37}$ with as few by-products as possible, iii) ideally with some luminescent properties in order to allow its future optical detection on surfaces, iv) but also a versatile platform allowing easy ligand substitution in order to tune and optimize all the above properties.

Back in the literature we have found the target molecule in a 2006 paper of Bunzli and coworkers $^{38}$ that reports a small dimer of formula $\left[\mathrm{Ln}(\mathrm{hfac})_{3} \mathrm{PyNO}-\mathrm{CN}\right]_{2}$ (Figure 1), made of a Ln$\beta$-diketonate $\left(\operatorname{Ln}^{\mathrm{III}}(\mathrm{hfac})_{3}\right.$ with $\mathrm{hfac}^{-}=$hexafluoroacetylacetonate $\left.{ }^{-}\right)$and a pyridine- $N$-oxide ligand (4-cyanopyridine- $N$-oxide). This heteroleptic molecule, called here LnPyNO-CN, is made of two $\operatorname{Ln}(\mathrm{hfac})_{3}$ molecules coordinated via the pending oxygen atom of two $\mathrm{N}$-oxide-based ligands. Regarding the $\mathrm{Ln}^{\mathrm{III}}$ ion, the hfac- ligands act as ancillary ligands and the $\mathrm{N}$-oxide as bridging ligands. This molecule has four main properties: i) the coordination environment of the $\mathrm{Ln}^{\mathrm{III}}$ ion is a very symmetric square antiprism $\left(\mathrm{SAPR}-8\right.$ with $\left.\mathrm{CShM}^{39}=0.726\right)$ that, if all coordinating atoms are electrostatically equivalent, can give rise to SMM behavior, ii) the Ln-Ln distance is small (around $4.1 \AA$ ) so that antiferromagnetic (AF) coupling is observed on the $\mathrm{Gd}^{\mathrm{III}}$ derivative, iii) the molecule is relatively small with 36 fluorine atoms around the two lanthanide ions that provide good evaporability and the dimer is partially sublimated at $190^{\circ} \mathrm{C}$ under atmospheric pressure, iv) the ligands can act as antenna to efficiency sensitize the luminescence emission of the $\mathrm{Sm}^{\mathrm{III}}, \mathrm{Eu}^{\mathrm{III}}, \mathrm{Tb}^{\mathrm{III}}$, Dy ${ }^{\mathrm{III}}$ and Tm${ }^{\mathrm{III}}$ ions. ${ }^{38}$ Consequently, the LnPyNO-CN platform fitted with most of our requisites even if no information about the SMM properties of the Dy ${ }^{\mathrm{III}}$ or $\mathrm{Tb}^{\mathrm{III}}$ derivatives were provided. 


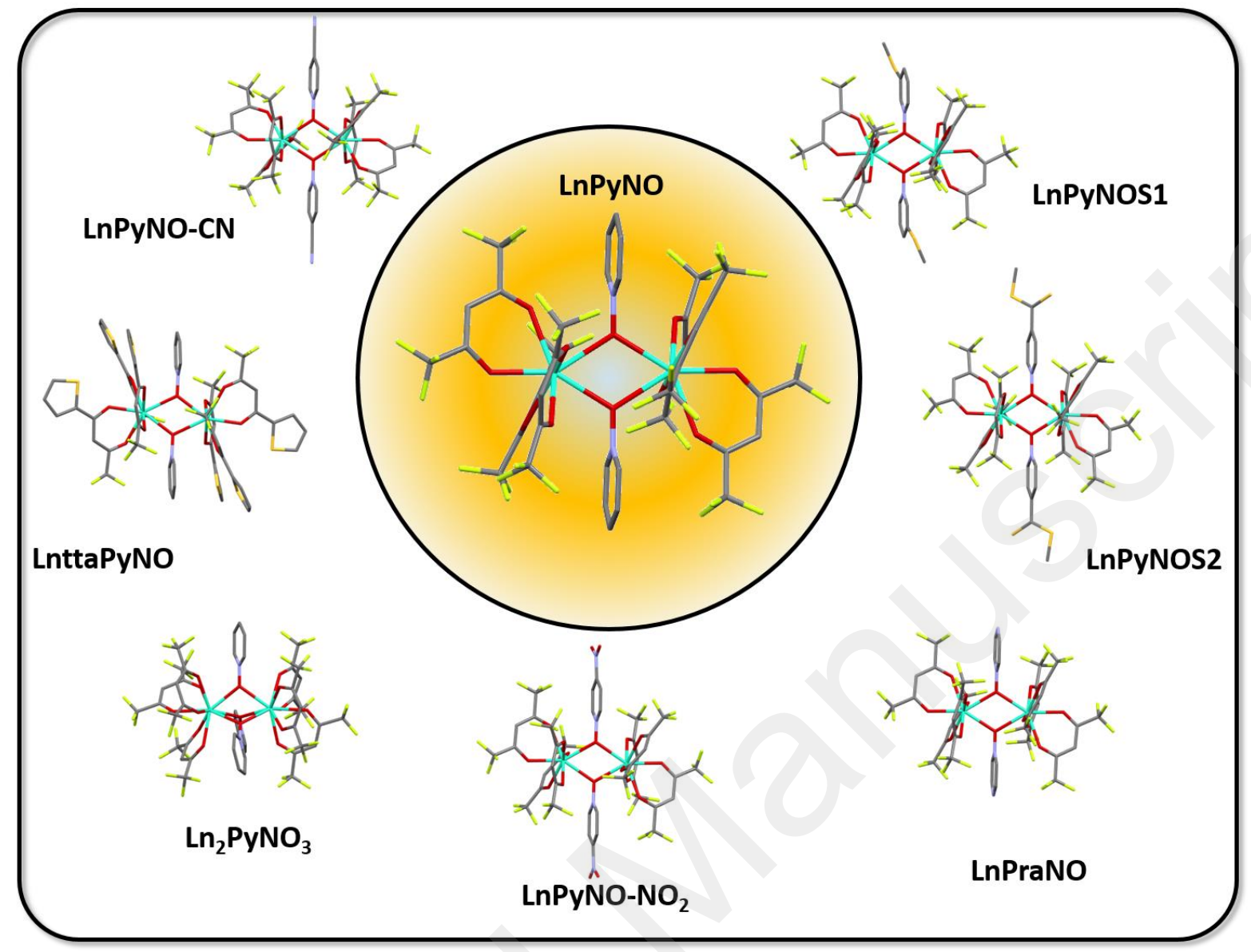

Figure 1. Representation of the dimers LnPyNO,${ }^{1,4}$ LnPyNOS1, ${ }^{40}$ LnPyNOS2, ${ }^{40}$ LnttaPyNO, ${ }^{2}$ $\operatorname{Ln}_{2} \mathrm{PyNO}_{3},{ }^{41}$ LnPyNO-NO $2,{ }^{3}$ LnPraNO,${ }^{5}$ together with LnPyNO-CN ${ }^{38}$ the seminal dimer that inspired the study; see text for abbreviations.

We thus synthesized analogous dimers called LnPyNO using hfac ${ }^{-}$as ancillary ligands and bare pyridine- $N$-oxide ligand as bridging ligands. Indeed, the cyano group of LnPyNO-CN is not driving the molecular geometry so we could remove it to reduce the molecular weight and enhance the sublimation properties. We then focused our investigation on the Dy ${ }^{\mathrm{III}}$ derivative (DyPyNO) that is the more likely to show a SMM behavior. As expected, the geometry of DyPyNO is highly similar to the one of DyPyNO-CN with very symmetric square antiprism environment (SAPR-8 with $\mathrm{CShM}=0.757)$ and small Dy-Dy distances $(4.07 \AA)($ Table S1 and Figure 2). 
As anticipated, DyPyNO has enhanced sublimation properties with thermogravimetric analysis (TGA/DTA) that shows a much more complete and sharper weight loss than that of GdPyNO-CN (99.2\% weight loss at $280^{\circ} \mathrm{C}$ and 1 atm, Figure 2$)$. Additionally, powder X-ray diffraction (PXRD) shows that the sublimated and the pristine bulk compound have similar crystal structure. This means that once evaporated on a cold surface the dimers spontaneously reproduce the original crystal packing. Accordingly, this latter is highly thermodynamically favored and this is a strong asset to target the design of ordered films of molecules.

As for LnPyNO-CN, the LnPyNO family shows strong luminescence for the Eu ${ }^{\mathrm{III}}$ (red, quantum yield of 51\%), $\mathrm{Tb}^{\mathrm{III}}$ (green, 53\%) and $\mathrm{Dy}^{\mathrm{III}}$ (yellow, $0.1 \%$ ) derivatives. This is due to the efficient sensitization of the emissive levels of the lanthanides by ligand's triplet states. Both pyridine- $N$-oxide and $\beta$-diketonates are good antennas for lanthanide emission. ${ }^{42,43}$ In our case, absorption and excitation spectra show that the most efficient sensitization band is the $\pi(\mathrm{N}-$ O)- $\pi^{*}(\mathrm{Py})$ of the $N$-oxide ligand $(\lambda=342 \mathrm{~nm}) .{ }^{30}$ 


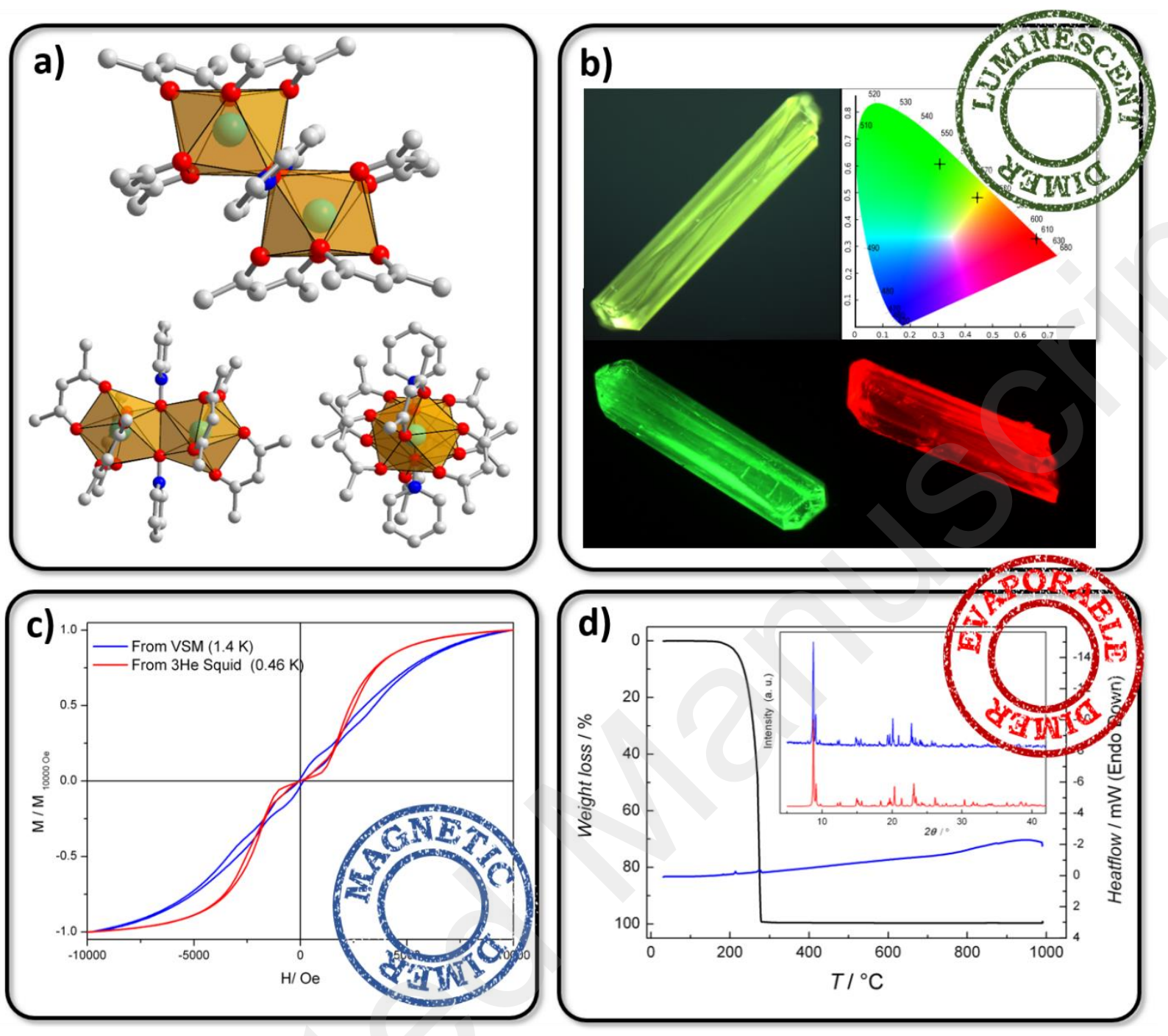

Figure 2. Representation of the main features of the LnPyNO dimers: a) symmetry of the $\operatorname{Ln}^{\text {III }}$ ion environment ( $\mathrm{F}$ and $\mathrm{H}$ atom omitted) b) pictures under UV illumination $(\lambda=312 \mathrm{~nm})$ of millimetric crystals of the Dy (top), Tb (bottom left) and Eu (bottom right) derivatives c) magnetic hystereses (magnetic field sweep rate of 18 Oe. $\mathrm{s}^{-1}$ and $\mathrm{T}=0.46 \mathrm{~K}$ (red) and $200 \mathrm{Oe} . \mathrm{s}^{-1}, \mathrm{~T}=1.4 \mathrm{~K}$ (blue)) that shows the double constriction characteristic of AF coupled dimers d) TGA/DTA analysis that shows a total weight loss around $280^{\circ} \mathrm{C}$ under 1 atm and PXRD patterns that evidence the similar crystal structure of the evaporated and bulk powders. ${ }^{1}$ Adapted with permission from reference 1. Copyright 2012 John Wiley and Sons. 
As anticipated, DyPyNO behaves as a SMM. We recall here that there are several figures of merit to qualify a SMM:

-First, the energy barrier for spin reversal ( $\mathrm{U}_{\text {eff }}$ ): the bigger is the barrier, the higher is the temperature at which the molecule can have a magnetic memory. It is determined by fitting the temperature dependence of the relaxation time $(\tau)$ with an Arrhenius law $\left(\tau=\tau_{0} \exp \left(U_{\text {eff }} / k_{B} T\right)\right.$, with $\tau_{0}$ the characteristic relaxation time and $\mathrm{k}_{\mathrm{B}}$ the Boltzmann constant).

-Second, the distribution of the relaxation times $(0<\alpha<1)$ that is obtained by fitting the relaxation time by a modified Debye law. The closer to zero $\alpha$ is, the better it is, because all molecules relaxes simultaneously.

-Third, the blocking temperature $\left(T_{B}\right)$. It cannot be extrapolated from the Arrhenius law because many parasitic relaxing phenomenon (QTM, Raman, Direct) become relevant at low temperature. $\mathrm{T}_{\mathrm{B}}$ can be determined as the temperature i) where Zero-Field Cooled/Field Cooled (ZFC/FC) curves diverges ii) where the ascending and descending branch of a magnetic hysteresis do not superimpose (provided that magnetic field sweep rate is slow enough when compared to the measurement) iii) where the relaxation time $\tau$ is $\tau=100 \mathrm{~s}$. This last is the most reliable parameter because it does not depend of the measurements conditions.

Consequently, an ideal SMM has a high $\mathrm{U}_{\text {eff }}$ (its limit is $\approx 3000 \mathrm{~K}$ for an isolated $\mathrm{Dy}{ }^{\mathrm{III}}$ in a theoretical $[\mathrm{Dy}-\mathrm{O}]^{+}$molecule), ${ }^{44}$ a very low $\alpha$ and a high $\mathrm{T}_{\mathrm{B}}$ because it hosts very few parasitic magnetic relaxation pathways.

On DyPyNO, slow magnetic relaxation is observed between 1.8 and $15 \mathrm{~K}$ with $\mathrm{U}_{\text {eff }}=167 \mathrm{~K}$, $\tau_{0}=1.87 \times 10^{-12} \mathrm{~s}$ and $\alpha_{2 \mathrm{~K}}=0.05$ (Table S2 and Figure 3). It was competitive with the highest performing SMMs in the literature at that time, also because this magnetic relaxation is observed 
in absence of external magnetic field. This means that, contrary to most of Dy-SMM, zero-field fast magnetic relaxation pathways operates but is somewhat slowed down in the dimer.
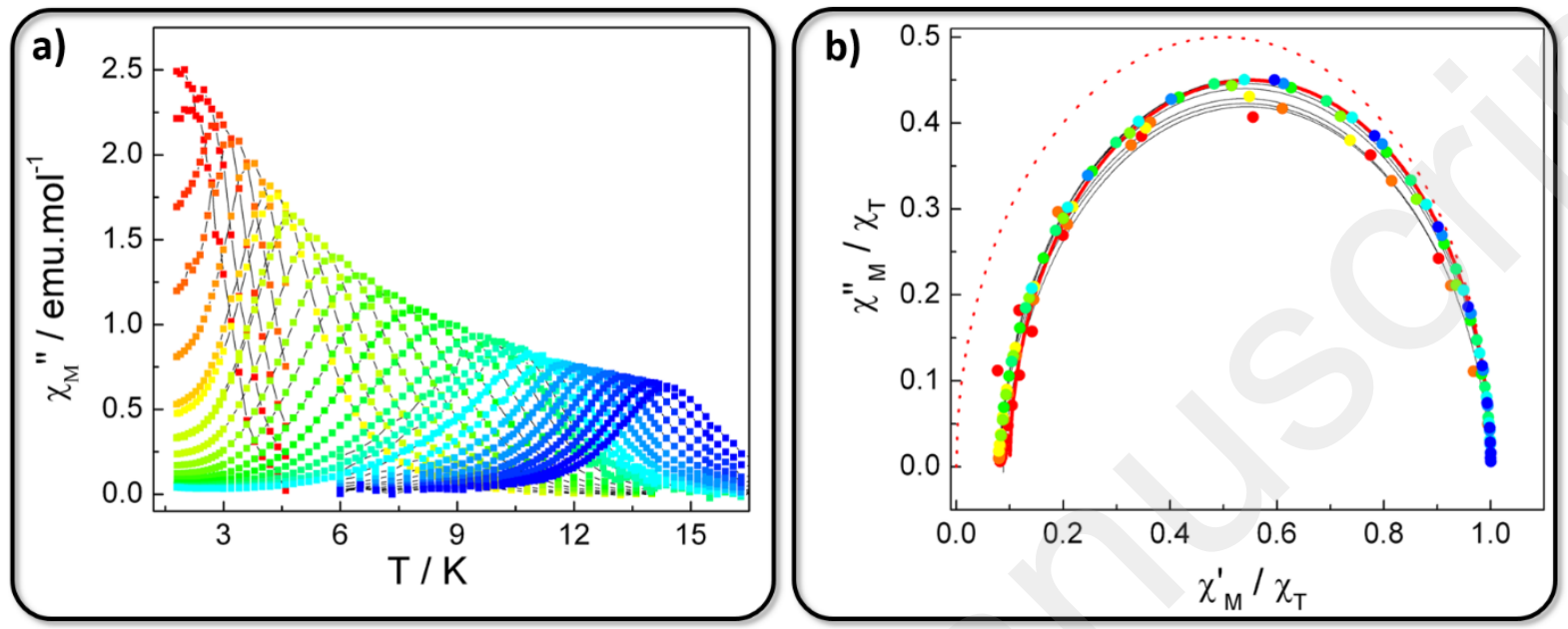

Figure 3. a) Temperature dependence of the out-of-phase component of the magnetic susceptibility from $0.5 \mathrm{~Hz}$ (red) to $70 \mathrm{kHz}$ (blue). b) Normalized Argand plot in the $3-11 \mathrm{~K}$ range with lines that are best fits with Debye model and dotted line the simulation of a perfect relaxation process ( $\alpha=0$ and $100 \%$ relaxing fraction). ${ }^{1}$ Adapted with permission from reference 1 . Copyright 2012 John Wiley and Sons.

DyPyNO magnetic hysteresis has a very peculiar shape (Figure 2). It shows two constrictions: one in zero-field (typical of an antiferromagnet, where a plateau is expected for $\mathrm{H}=0$ ) and one at moderate field (typical of a dimer, visible at $\mathrm{H}=\mathrm{H}_{\text {crossing). This last corresponds to an acceleration }}$ of the magnetic relaxation due to the crossing between the ground state and the first excited state of the dimer. In the Ising approximation $\left(S=1 / 2, g_{z}=20\right), H_{\text {crossing }}=-J /\left(2 g_{z} \beta\right)$ with $J$ the AF interaction between the two Dy III ions. Accordingly on DyPyNO, $\mathrm{H}_{\text {crosssing }}=1800$ Oe and $\mathrm{J}_{\text {crossing }}=-3.36 \mathrm{~cm}^{-1}$. This is close to the values obtained by ab-initio calculations $\left(\mathrm{g}_{\mathrm{z}}=19.53\right.$ and $\mathrm{J}_{\text {total }}=\mathrm{J}_{\mathrm{exch}}+\mathrm{J}_{\mathrm{dip}}=-0.25-$ $\left.2.44=-2.69 \mathrm{~cm}^{-1}\right)^{2}$ 


\section{b. Compound optimization (I): 3D organization of the dimers ${ }^{41}$}

Overall DyPyNO is an efficient luminescent and evaporable SMM. Before going straight to its deposition on surface we investigated the tunability of this platform to explore how its sublimation ability, magnetic and luminescent properties can be optimized.

Our first optimization strategy relied on tuning the Dy ${ }^{\mathrm{III}}$ coordination number. DyPyNO building blocks (Dy(hfac) $)_{3} \cdot 2 \mathrm{H}_{2} \mathrm{O}$ and pyridine- $N$-oxide) are neutral so the synthesis of the dimer is not driven by electro-neutrality but by stoichiometry and thermodynamics. Keeping this last unchanged (similar reaction and crystallization conditions) we tuned the stoichiometry and we were able to obtain another dimer's family of formula $\left(\mathrm{Ln}(\mathrm{hfac})_{3}\right)_{2}(\mathrm{PyNO})_{3}$ (latter abbreviated Dy2 $_{2} \mathbf{P y N O}_{3}$ ). In these dimers not two but three pyridine- $N$-oxide ligands bridge the Dy ${ }^{\mathrm{III}}$ ions. This coordination mode slightly change the Ln-Ln distance $\left(3.86 \AA\right.$ for $\mathbf{D y}_{2} \mathbf{P y N O} \mathbf{O}_{3}$ instead of $4.07 \AA$ for DyPyNO) but most of all it modifies the Dy ${ }^{\mathrm{III}}$ coordination environment because Dy ${ }^{\mathrm{III}}$ ions are now nine-coordinated. In $\mathbf{D y}_{2} \mathbf{P y N O}_{3}$ coordination polyhedrons are spherical capped square antiprism (CSAPR-9) with CShM= 0.927 for Dy1 and CShM $=0.605$ for Dy2 (it was SAPR-8 with $\mathrm{CShM}=0.757$ for DyPyNO).

This modification of the dimer geometry has a negative effect on the SMM properties. SMM behavior is hardly observable in absence of external magnetic field and in-field measurements $\left(\mathrm{H}_{\mathrm{dc}}=1900 \mathrm{Oe}\right)$ show weak figures of merit $\left(\mathrm{U}_{\mathrm{eff}}=24.4 \mathrm{~K}, \tau_{0}=3.18 \times 10^{-6} \mathrm{~s}, \alpha_{2 \mathrm{~K}}=0.45\right.$ and $\tau_{2 \mathrm{~K}}=$ 0.010s). However, beyond this weak SMM behavior, the topology of the triple-bridged dimers deserves some attention. In $\mathbf{D y}_{2} \mathbf{P y} \mathbf{N O}_{3}$ the three bridging ligands points at $120^{\circ}$ from each other and are perpendicular to the Dy-Dy direction. Thus, we anticipated that such dimer could be a good building block to form an extended molecular structure (possibly 2D) made of dimers organized in a molecular lattice. We changed the monodentate pyridine- $N$-oxide for the linear and 
bidentate 4,4 'bipyridine- $N$-oxide ligand. This strategy worked fairly well and we readily obtained a network of triply bridged dimers of formula $\left[\left(\mathbf{D y}_{2} \mathbf{P y N O}_{3}\right)(\mathbf{b i P y N O})\right]_{\infty}$ (Figure 4$) .{ }^{41}$ The dimers have similar geometric features as $\mathbf{D y}_{2} \mathbf{P y N O}_{3}$ and are connected one to another by the 4,4'bipyridine- $N$-oxide ligands. The extended molecular architecture is not $2 \mathrm{D}$ as expected but an extended 3D interpenetrated network ( $\mathrm{ThSi}_{2}$ family and (10,3)-b Wells point symbol). Interestingly, despite this huge effect on the crystal packing and on the dimers organization, $\left[\left(\mathbf{D y}_{2} \mathbf{P y N O}_{3}\right)\left(\mathbf{b i P y N O}_{2}\right]_{\infty}\right.$ still shows an in-field $\mathrm{SMM}$ behavior $\left(\mathrm{U}_{\mathrm{eff}}=10.3 \mathrm{~K}, \tau_{0}=1.25 \times 10^{-5} \mathrm{~s}\right.$, $\alpha_{2 \mathrm{~K}}=0.45$ and $\left.\tau_{2 \mathrm{~K}}=3.99 \times 10^{-4} \mathrm{~s}\right)$.

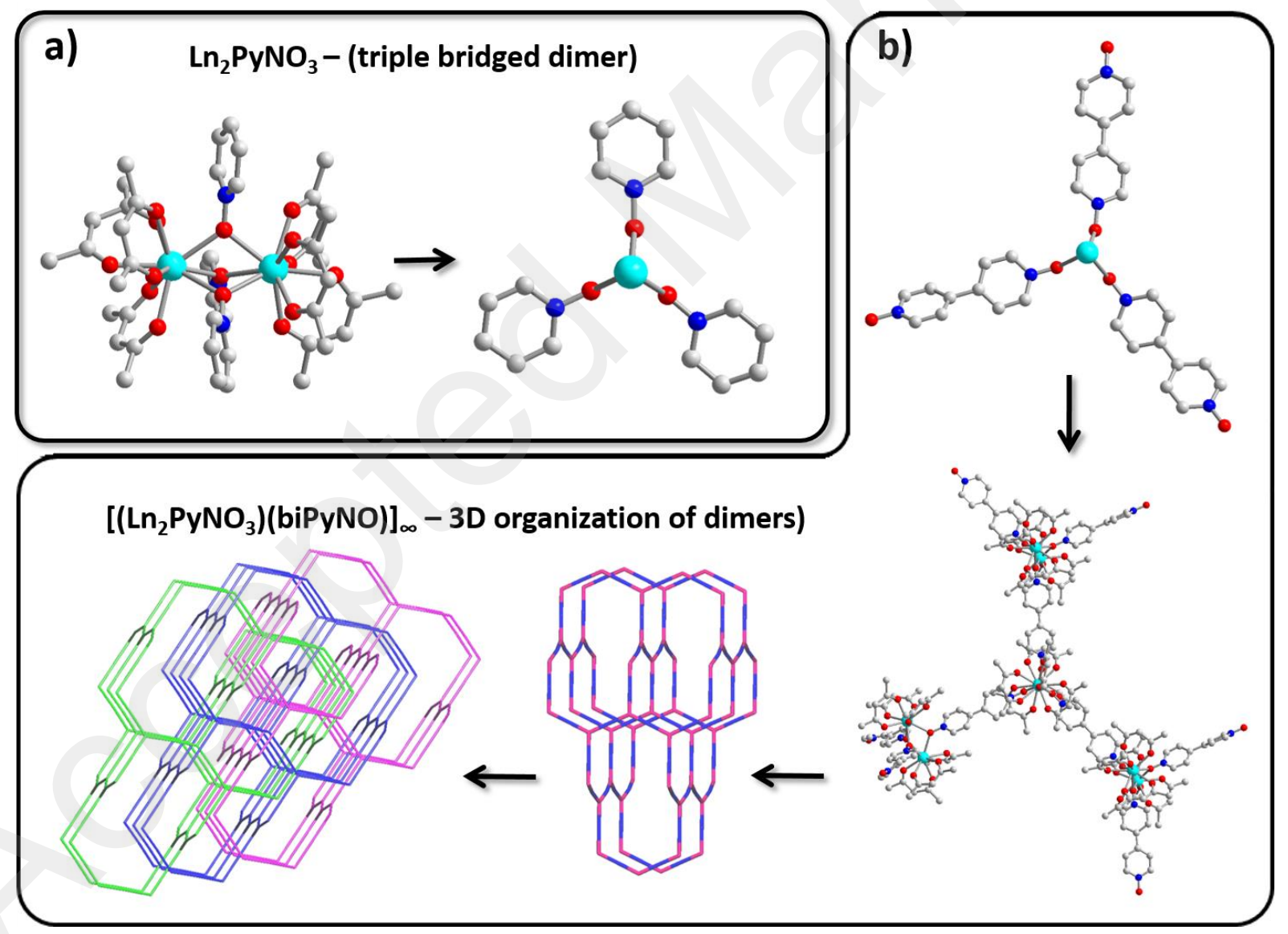

Figure 4. a) Representation of the triple bridged dimer $\mathbf{L n}_{2} \mathbf{P y N O}_{3}$ (left) and its view along the Ln-Ln direction with only the bridging ligand represented (right) b) View of 
$\left[\left(\mathbf{L n}_{2} \mathbf{P y N O}_{3}\right)(\mathbf{b i P y N O})\right]_{\infty}$ along the Ln-Ln direction with only the bridging ligand represented (top) view of the molecular structure extension featuring connected dimers (bottom right) topological representation of the interpenetrated network with dimers as pink angles and 4,4'BipyNO as purple sticks (bottom left). ${ }^{41}$ Adapted with permission from reference 41. Copyright 2015 American chemical Society.

\section{c. Compound optimization (II): playing with ancillary ligands ${ }^{2}$}

It is then clear that triple-bridged dimers are not good targets. We choose another optimization strategy based on the modification of the $\beta$-diketonate ancillary ligands to tune the Dy ${ }^{I I I}$ electrostatic environment. We changed the symmetrical hfac ligand for asymmetrical $\mathrm{tta}^{-}$ (2-thenoyltrifluoroacetonate). The corresponding dimer called DyttaPyNO has similar Dy-Dy distances than DyPyNO (4.15 and $4.07 \AA$ respectively) but a drastically different coordination environment (Figure 5). Indeed, the thenoyl parts of the $\beta$-diketonate are known to interact electrostatically three-by-three when coordinated to a lanthanide ion. ${ }^{45}$ This drives the Dy coordination polyhedron far from the square antiprism observed on DyPyNO and a very symmetric triangular dodecahedron is observed (TTD-8 CShM=0.403). Using ab-initio calculation we evidenced that this strong geometric change improved both the value of the Dy anisotropy and the separation of the ground and first excited state $\left(\mathrm{g}_{\mathrm{z}}=19.58,160 \mathrm{~cm}^{-1}\right.$ and 19.53 , $121 \mathrm{~cm}^{-1}$ for DyttaPyNO and DyPyNO respectively). Such difference is visible on the magnetic measurements and DyttaPyNO relaxes slower than DyPyNO on all the investigated temperature range. 

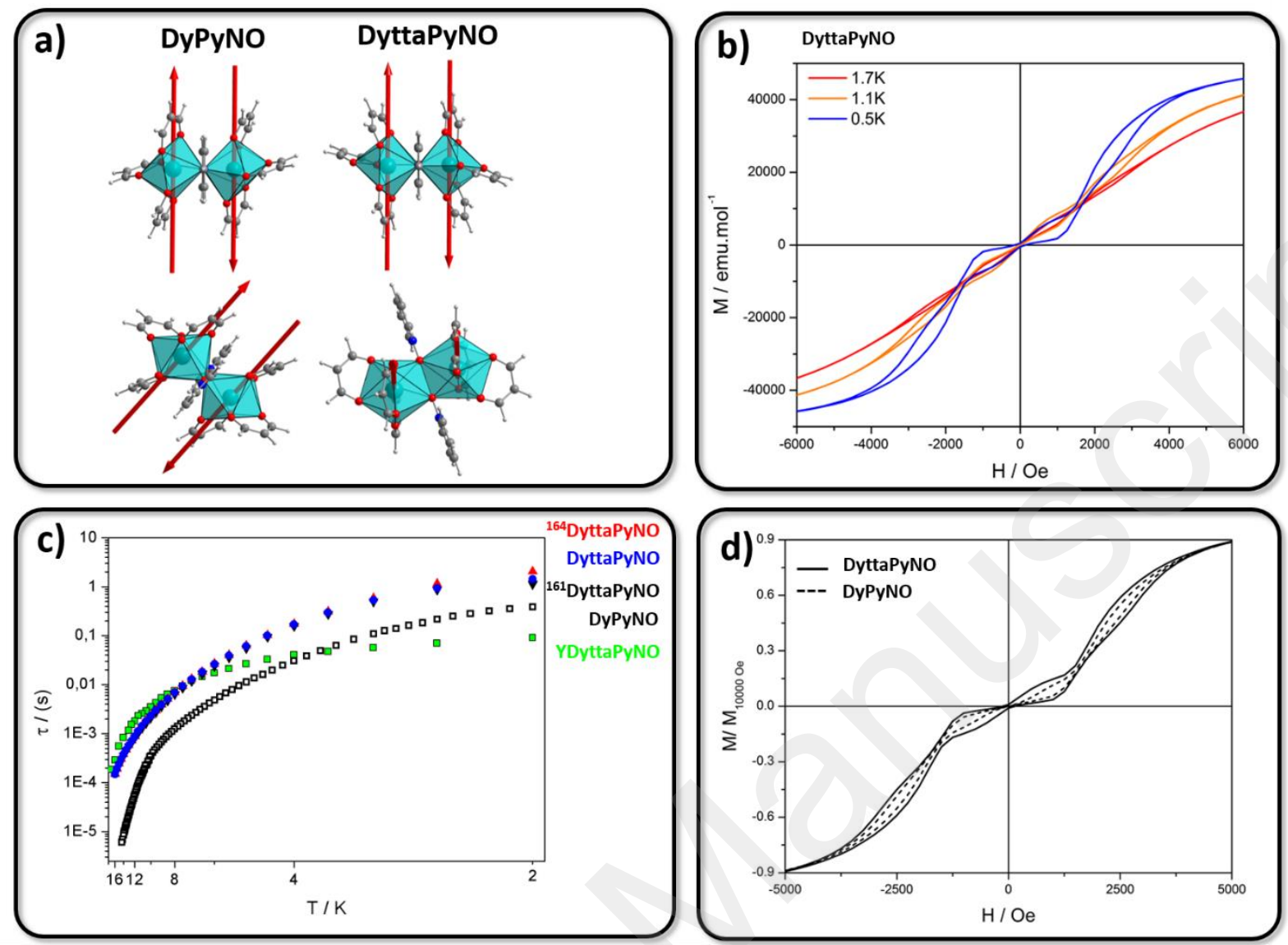

Figure 5. a) Simplified representation of the dimers highlighting the Dy ${ }^{\text {III }}$ coordination environment differences but the similar easy-magnetic axes orientation, perpendicular to the DyDy direction b) Hysteresis measurement of DyttaPyNO at various temperatures with a field sweep rate of 18 Oe.s ${ }^{-1}$ c) Arrhenius plot of the DyttaPyNO derivatives and DyPyNO d) Comparison of the magnetic hystereses at $0.5 \mathrm{~K}$ of DyPyNO and DyttaPyNO. ${ }^{2}$ Adapted with permission from reference 2. Copyright 2018 John Wiley and Sons.

It is worth noticing that despite these very different coordination geometries, the easy magnetic axes of both dimers are extremely similar. They are oriented almost perpendicular to the Dy-Dy direction and confirm that this orientation is driven by the molecular electrostatics and not by the 
local coordination geometries (Figure 5). Easy magnetic axis orientation allows to estimate the intramolecular dipolar coupling $\left(\mathrm{J}_{\mathrm{dip}}=-2.36 \mathrm{~cm}^{-1}\right)$ while ab-initio calculations estimate the total coupling as $\mathrm{J}_{\mathrm{total}}=-2.86 \mathrm{~cm}^{-1}$. This provides an exchange coupling of $\mathrm{J}_{\mathrm{exch}}=-0.50 \mathrm{~cm}^{-1}$. Overall, the AF coupling is slightly higher in DyttaPyNO $\left(\mathrm{J}_{\text {total }}=\mathrm{J}_{\text {exch }}+\mathrm{J}_{\mathrm{dip}}=-0.50-2.36=-2.86 \mathrm{~cm}^{-1}\right)$ than in DyPyNO $\left(\mathrm{J}_{\text {total }}=\mathrm{J}_{\text {exch }}+\mathrm{J}_{\text {dip }}=-0.25-2.44=-2.69 \mathrm{~cm}^{-1}\right)$ when analyzed at the same level of calculation.

To confirm the influence of the strength of the AF interaction on the quality of the SMM behavior we heavily doped DyttaPyNO with YIII to obtain YDyttaPyNO in a $0.83 / 0.17 \mathrm{Y} / \mathrm{Dy}$ ratio. Such a high doping ratio reduces traces of Dy-Dy dimers in the sample. This is confirmed by ac magnetic measurements where no reminiscent peaks of pure Dy dimers are observed. This is an important point that shows that SMM behavior of Dy dimers cannot be optimized by dilution in an isomorphous diamagnetic matrix as commonly done on monometallic SMM. ${ }^{46,47}$ Concerning YDyttaPyNO, the magnetic relaxation is similar to the one of DyttaPyNO above 10K but as the temperature is lowered, a strong quantum tunneling of the magnetization (QTM) is observed and the temperature dependence of the relaxation time vanishes. Overall, the doped dimers relax two order of magnitude faster than their pure Dy analogues. This confirms that the Dy-Dy AF interaction plays a fundamental role in reducing the occurrence of QTM in this family of dimers. This is in line with what was observed on other SMM that host such significant magnetic interactions. $^{48-53}$

In previous works on monometallic Dy-SMM, we have shown that the isotopic composition can enhance or worsen the magnetic relaxation of a given molecule. ${ }^{54}$ Natural Dy ${ }^{\mathrm{III}}$ is mainly composed of four stable isotopes: ${ }^{161} \mathrm{Dy}(\mathrm{I}=+5 / 2),{ }^{162} \mathrm{Dy}(\mathrm{I}=0),{ }^{163} \mathrm{Dy}(\mathrm{I}=-5 / 2),{ }^{164} \mathrm{Dy}(\mathrm{I}=0)$. Consequently, a Dy-SMM relaxes proportionally to its average isotopic composition. We demonstrated that this contribution can be de-convoluted, and that a SMM made of nuclear spin-free ion $\left({ }^{164} \mathrm{Dy}\right)$ relaxes 
significantly slower in zero-field than its nuclear spin-active analogue $\left({ }^{161} \mathrm{Dy}\right)$. This is due to the suppression of the hyperfine interaction that usually enhances zero-field fast-tunneling. ${ }^{55,56} \mathrm{We}$ tested this approach on DyttaPyNO by synthesizing ${ }^{161}$ DyttaPyNO and ${ }^{164}$ DyttaPyNO. Very small improvement has been observed and a small trend between nuclear spin-active, natural and nuclear spin-free Dy ${ }^{\mathrm{III}}$ is seen $\left(\tau_{2 \mathrm{~K}}=1.8,2.2,3.0 \mathrm{~s}\right.$ for ${ }^{161}$ DyttaPyNO, DyttaPyNO and ${ }^{164} \mathrm{DyttaPyNO}$ respectively). This experimentally demonstrates that the effect of the hyperfine contribution is considerably smaller than all other effects in a coupled system and that isotopic substitution is valuable only on monometallic SMM.

\section{3) From compound to material: dimers for surface deposition}

\section{a. Compound optimization (III): playing with bridging ligands to build anchorable dimers ${ }^{40}$}

Surface deposition is a necessary step to turn these dimers into materials. A conventional route is to functionalize SMMs with thiol groups to graft them on $\mathrm{Au}(111)$ surfaces $^{57-59}$ in order to form a magnetic molecular deposit. On the dimer series, the easiest way to do so is to modify the pyridine bridging ligand. In fact, a similar approach on the ancillary $\beta$-diketonates could provide strongly distorted Dy ${ }^{\mathrm{III}}$ environments or undesired monomeric complexes because of steric hindrance. We have thus modified DyPyNO by using two different thio-based anchoring groups on the pyridine- $N$-oxide ligand: 3-methylsulfanyl-pyridine- $N$-oxide and 4-methylcarbodithioatepyridine- $N$-oxide to produce DyPyNOS1 and DyPyNOS2 respectively. ${ }^{40}$ As expected, on both dimers the Dy coordination environment is very similar to the one of DyPyNO (Table S1) because its geometry is mainly driven by the $\beta$-diketonate arrangements, as demonstrated with

\section{DyttaPyNO.}


As on all reported dimers, the easy magnetic axes of DyPyNOS1 and DyPyNOS2 are perpendicular to the Dy-Dy direction and very similar AF coupling are observed on both dimers $\left(\mathrm{J}_{\text {total }}=\mathrm{J}_{\text {dip }}+\mathrm{J}_{\text {exch }}=-2.52-0.125 \mathrm{~cm}^{-1}=-2.65 \mathrm{~cm}^{-1}\right.$ for DyPyNOS1 and $\mathrm{J}_{\text {total }}=\mathrm{J}_{\text {dip }}+\mathrm{J}_{\mathrm{exch}}=-2.49$ $0.50 \mathrm{~cm}^{-1}=-2.99 \mathrm{~cm}^{-1}$ for DyPyNOS2, Table S2). Consequently, the SMM properties of the dimers are similar $\left(\tau_{2 \mathrm{~K}}=0.07\right.$ and 0.04 for DyPyNOS1 and DyPyNOS1 respectively). Unfortunately, we have not been able to deposit these dimers by dip-coating on $\mathrm{Au}(111)$ surfaces probably because the thio-substitution diminishes the robustness of the dimers during the wet part of the deposition process.

\section{b. Molecular magnetic films of dimers ${ }^{4}$}

We thus turned back to our genuine DyPyNO and relied on its excellent sublimation properties. At that time only two families of SMMs were anchorable on surface: derivatives of a tetranuclear complex of $\mathrm{Fe}^{\mathrm{III}} 59,60$ and derivatives of a mononuclear complex of $\mathrm{Tb}^{\mathrm{III}}$ (latter named $\mathrm{Tb}\left(\mathrm{Pc}_{2}\right)$, where $\mathrm{Pc}=$ phtalocyanine). ${ }^{61,62}$ This latter attracted lot of attention ${ }^{63,64}$ because of its simple deposition protocol, easy chemical tuning and high magnetic anisotropy. However, as the $\mathrm{TbPc}_{2}$ molecules are stacked in films, they lose their magnetic properties due to strong electrostatic and geometric interactions with the substrates. ${ }^{35,65,66}$

We formed thick films of DyPyNO on gold evaporated on mica (DyPyNO/Au/Mica) in a vacuum chamber $\left(1.10^{-7}\right.$ mbar $)$ under moderate heating $(380 \mathrm{~K})$ at a deposition rate of $1.3 \AA . \mathrm{s}^{-1} .4$ Parallel evaporation on glass provide an analogue for AFM scratching measurements (Figure 6) and the thickness of the film is $\approx 300 \mathrm{~nm}$ with a roughness of $\approx 20 \mathrm{~nm}$. Grazing angle XRD analysis shows that these films are amorphous since no regular crystalline structure is detected. Many of the failed deposition of molecules on surfaces are due to molecule fragmentation during the evaporation process. Accordingly, we monitored carefully the integrity of the dimers via X-Ray 
Photoelectron Spectroscopy (XPS) and Time of Flight Secondary Ion mass spectroscopy (ToFSIMS). XPS clearly demonstrated that the elemental composition of the film matches the one of the bulk DyPyNO powder. Similarly, ToF-SIMS studies unambiguously demonstrate that the sublimation does not alter the chemical composition of the molecule and once again, bulk and film behave in the same way. With this in mind, magnetic characterizations were undertaken and films and bulk DyPyNO showed a remarkably similar magnetic behavior (Figure 7 and 8). This means that, contrary to what was observed on $\mathrm{TbPc} 2$, no particular substrate-molecule interactions, that creates parasitic magnetic relaxation pathways at low $\mathrm{T}$, are observed. 

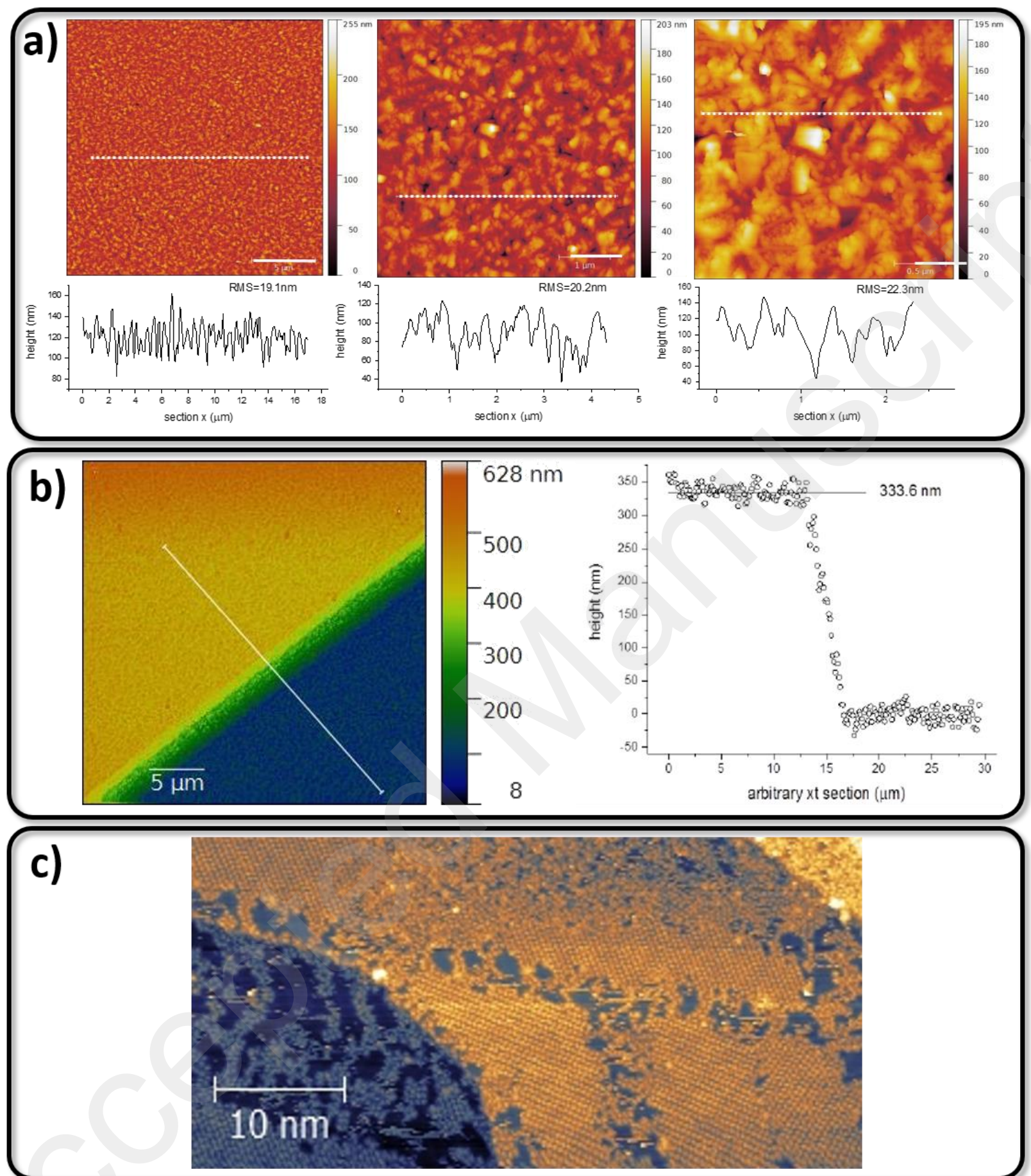

Figure 6. a) AFM characterization of the DyPyNO/Au/Mica films at various magnifications with the estimated roughness. b) AFM scratch test on the DyPyNO/Au/Mica thick film. ${ }^{4}$ c) STM image at $10 \mathrm{~K}$ of a sub-monolayer of DyPyNO molecules deposited on Au/Mica. ${ }^{67}$ Adapted with 
permission from reference 4 and 67. Copyright 2016 American Chemical Society \& 2019 Techniques de l’Ingénieur.

To elucidate the reason why DyPyNO films behave much better than TbPc2 ones we performed muons spin relaxation $(\mu \mathrm{SR}){ }^{4}$ Muons are elemental particles that behave as local magnetic probes once implanted in a sample (bulk or film). The monitoring of muons spin relaxation on our samples shows very similar results between bulk and films, confirming our magnetic measurements.

Additionally, low energy muons spin relaxation experiments (LE- $\mu \mathrm{SR})$ allow a muon implantation at varying depth in a thick film. On our samples, we clearly see that wherever the muon is implanted its relaxation remain unchanged and similar to the bulk compound (Figure 7). In particular, no specific variation near the film/substrate interface or close to the film/vacuum interface could be detected. This highlights a very homogenous molecular magnetic behavior in the films and let suppose a very controlled molecule arrangement in DyPyNO films. This is in contrast with what was seen on $\mathrm{TbPc} 2$ where the first layers of molecules lay on the surface while they progressively tilt perpendicular to the surface toward the film/vacuum interface. ${ }^{66}$

Overall, DyPyNO is among the very few example of SMM whose properties are preserved upon surface deposition. This is due first to the excellent sublimation properties of the molecules that combine a low molecular weight with a high number of fluorine atoms (36) that enhance sublimation ability. Second, the geometry of the molecule is a strong asset because DyPyNO is schematically a ball of fluorine atoms embedding two Dy ${ }^{\mathrm{III}}$ ions. This "chemical and electrostatic shielding" of the spin carriers avoids strong and deleterious interactions with the substrate as observed on TbPc2. It also allows a spontaneous and homogenous geometrical arrangement of the molecules and provides overall an efficient magnetic molecular material. 

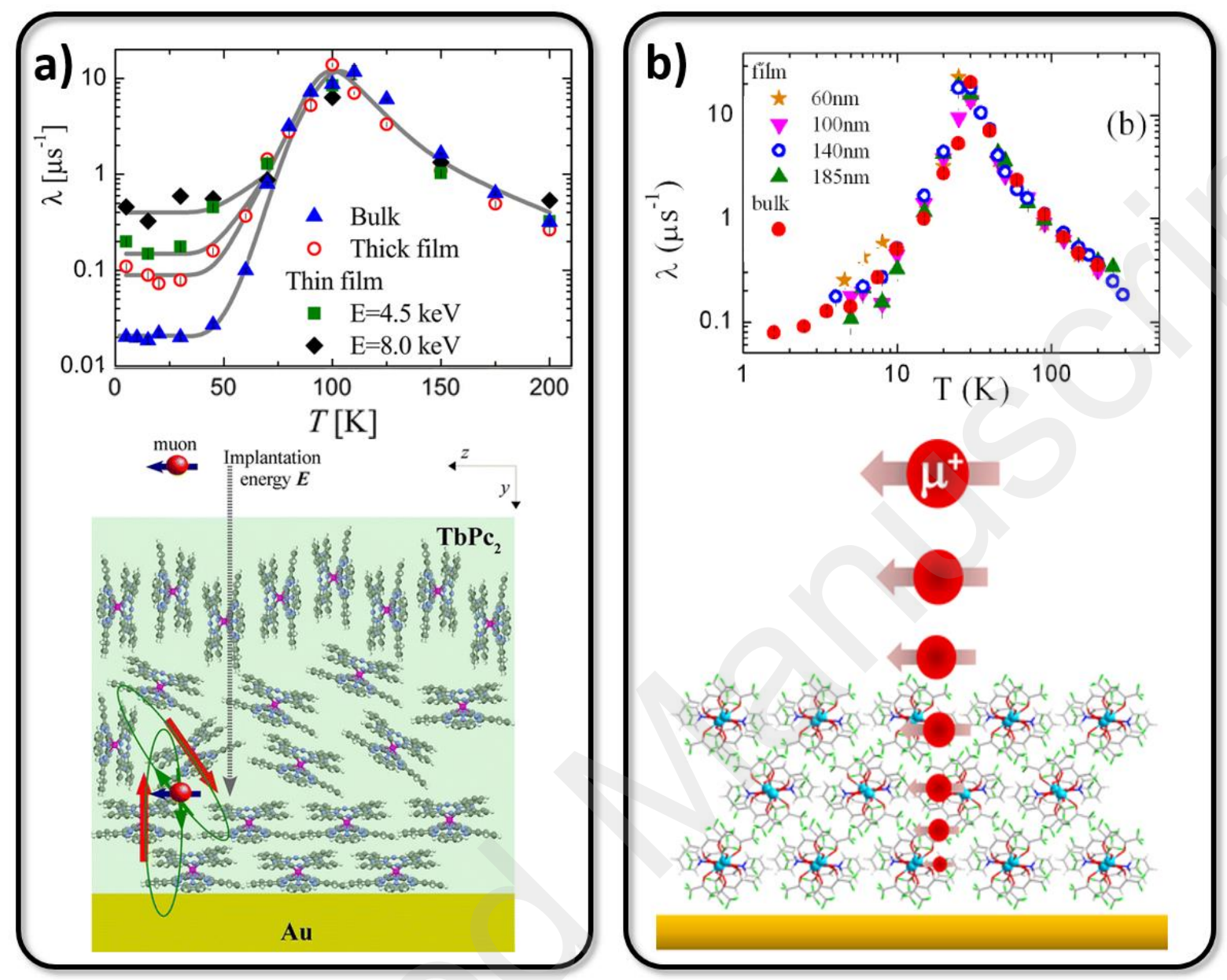

Figure 7. Temperature dependence of the relaxation rate $(\lambda)$ and schematic representation of the molecule organization on surface for a) $\mathrm{TbPc} 2$ film/Au/Mica ${ }^{66}$ b) DyPyNO film/Au/Mica. ${ }^{4}$ Adapted with permission from reference 4 and 66. Copyright 2012 and 2016 American Chemical Society.

c. Material optimization: playing with bridging ligands to enhance on-surface properties $^{3}$ 
It is then clear that the creation of sublimated thick film is the best route to date to form magnetic materials from these dimers. Consequently, dimers optimization cannot be done at the expense of their sublimation ability. We thus modified DyPyNO adding a $\mathrm{NO}_{2}$ electron-withdrawing group on the bridging ligand to form DyPyNO-NO${ }_{2}{ }^{3}$ Such approach is expected to influence the electrostatic surrounding of the Dy ${ }^{\mathrm{III}}$ ions via the strongly delocalized pyridine- $N$-oxide ligand but without enhancing too much the molecular weight of the molecule and without altering the number and geometric organization of the fluorine atoms.

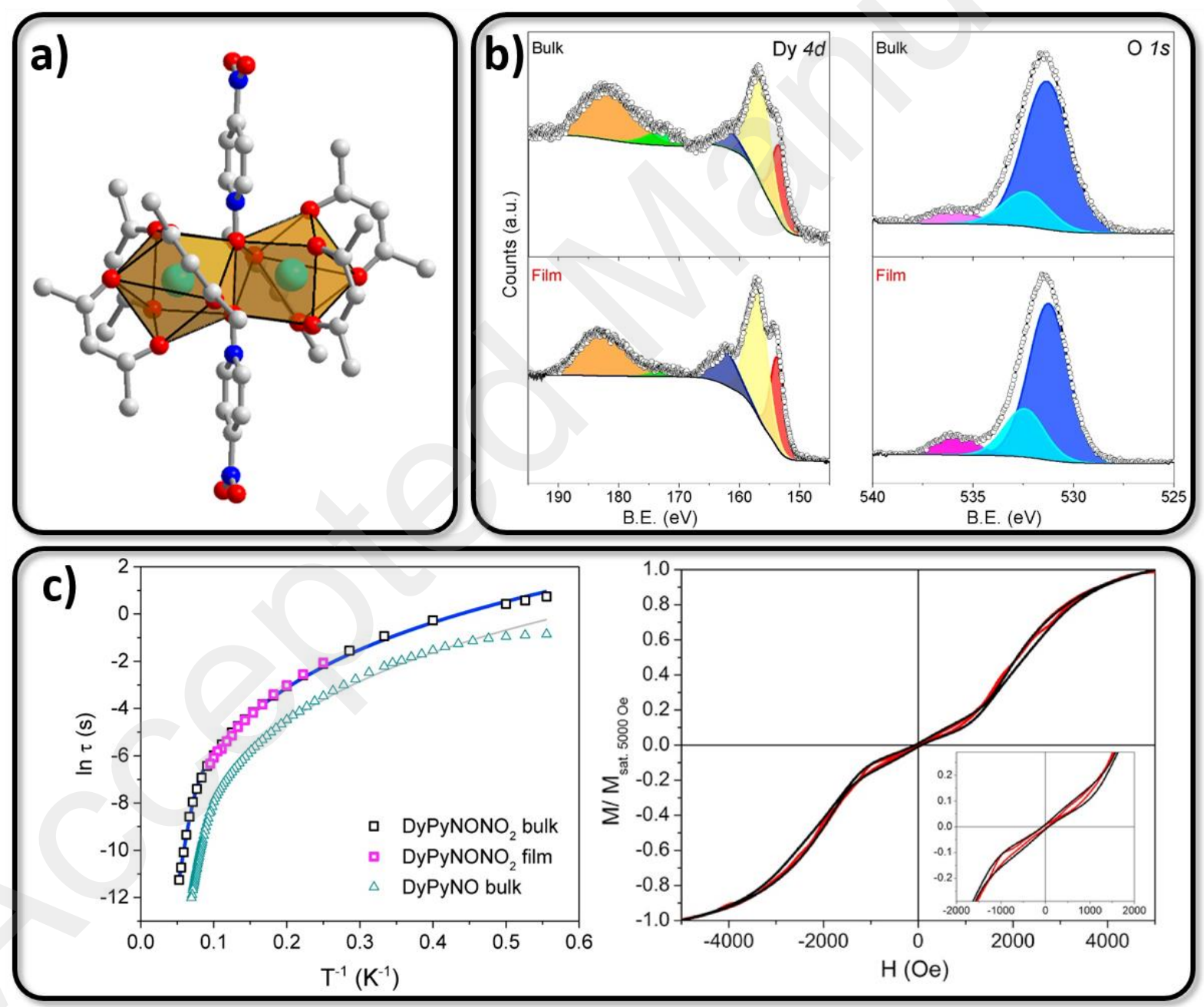


Figure 8. a) Representation of the DyPyNO-NO2 dimer b) XPS of Dy 4d and O 1s for DyPyNO$\mathrm{NO}_{2}$ bulk and film c) Arrhenius plot (left) and hysteresis measurement at $0.5 \mathrm{~K}$ and 18 Oe. $\mathrm{s}^{-1}$ for DyPyNO-NO2 bulk (black) and film (red) (right). ${ }^{3}$ Adapted with permission from reference 3. Copyright 2018 Elsevier.

This strategy works well and DyPyNO-NO2 shows an enhanced magnetic relaxation when compared to DyPyNO $\left(\mathrm{g}_{z}=19.56, \mathrm{~J}_{\text {total }}=-2.9 \mathrm{~cm}^{-1}, \tau_{0}=3.1 \times 10^{-10} \mathrm{~s}, \mathrm{U}_{\text {eff }}=204 \mathrm{~K}, \tau_{2 \mathrm{~K}}=1.54 \mathrm{~s}\right)$. It is thus one of the most optimized dimer from the series. Films of DyPyNO-NO2 can be formed with no particular chemical or geometric differences with DyPyNO films. Magnetic behavior of the films and the bulk are remarkably similar and almost superimposable hysteresis loops are observed at low temperature. Interestingly, the relaxing fraction of the film is $96 \%$ with a distribution of $\alpha=$ 0.24 that highlights that all the molecules of the film show a SMM behavior and almost relax at a similar rate. Overall, DyPyNO-NO2 films relax an order of magnitude slower than DyPyNO films. They form particularly robust and optimized magnetic materials that can be readily designed via a controlled and straightforward synthesis.

\section{4) From material to device: films of dimers for luminescence modulation in a solid-} state $^{5}$

Because the dimers can be easily sublimated over a surface, the creation of luminescent nanostructure can be targeted. Indeed, a plethora of luminescent material and devices made of Ln$\beta$-diketonate has been reported in the literature. ${ }^{68}$ During our synthetic overview of the dimer family, we observed that the visible emission of some dimers bearing Lewis basic coordinating groups on their pyridine rings was highly quenched in presence of metal ions. The most striking 
example was the dimer with pyrazine- $N$-oxide as bridging ligand, called LnPraNO (Figure 9), ${ }^{5}$ whose luminescence is strongly quenched by $\mathrm{Cu}^{2+}$ ions.

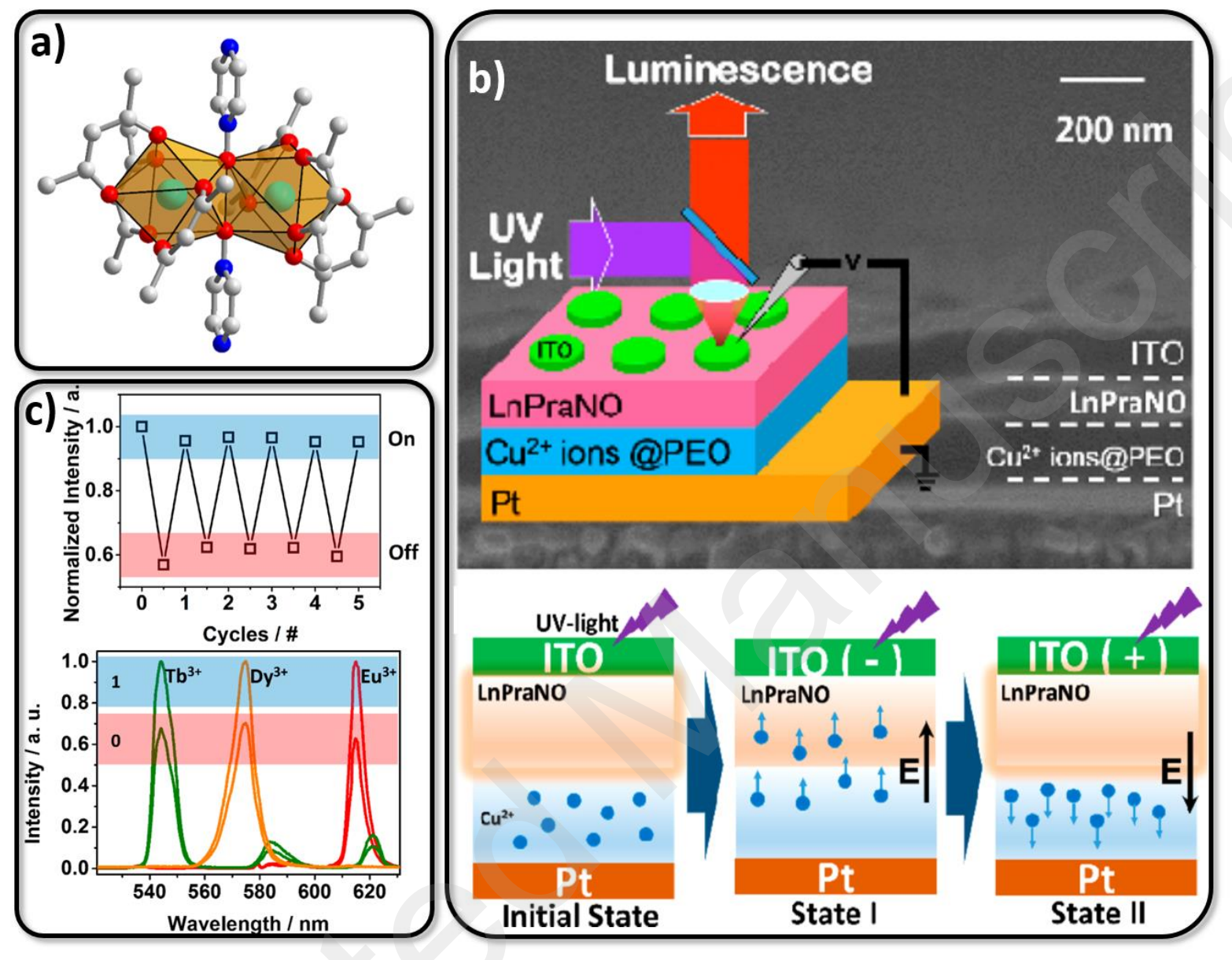

Figure 9. a) Representation of the DyPraNO dimer b) Cross-section SEM image of the ITO/LnPraNO/Cu ${ }^{2+} @$ PEO/Pt device and schematic illustration of the migration of the $\mathrm{Cu}^{2+}$ ions upon electric field c) Modulation of the photoluminescence intensity on the Tb-based device (top) and photoluminescence spectra with the maximum and minimum photoluminescence intensity on the Tb-, Eu- and Dy-devices (bottom). ${ }^{5}$ Adapted with permission from reference 5. Copyright 2016 American Chemical Society. 
We thus proposed a proof of concept solid-state device where a layer of LnPraNO is deposited on a copper-rich polyethylene oxide (PEO) layer. ${ }^{5}$ Once these two are sandwiched by indium tin oxide (ITO) electrodes, an electro-migration of $\mathrm{Cu}^{2+}$ ions across the $\mathbf{L n P r a N O}$ can be performed. Once the electric field is switched off, the luminescence of the whole device is monitored and clear luminescence quenching occurs when the layer is filled with $\mathrm{Cu}^{2+}$ ions. This is true whatever the layer is made of $\mathrm{Dy}^{\mathrm{III}}, \mathrm{Tb}^{\mathrm{III}}$ or Eu ${ }^{\mathrm{III}}$ ions. Electro-migration can be tailored back and forth across the LnPraNO layer and reversible modulation of the luminescence is then observed. While, the detailed mechanisms of electro-migration and luminescence quenching deserve more investigation, this proof-of concept device opens the way to solid-state optoelectronic devices where electric stimulus can write a data while a photo-luminescent readout is used. This could even be combined with the SMM properties of the dimers to enhance the coding ability of the device.

\section{5) Conclusion}

In this account, we review several years of work on luminescent and magnetic lanthanide dimers. These dimers combine a chemical simplicity and straightforward synthesis with excellent sublimation abilities, very strong luminescence and relevant SMM properties. We used the tools of coordination chemistry with ancillary or bridging ligand to tune their geometry, crystal packing, nuclear-spin composition, electrostatic surrounding and optimize their sublimation, magnetic and luminescent properties. We turned these compounds into molecular magnetic materials and thanks to large-scale facility techniques such as LE- $\mu$ SR we demonstrate how their controlled organization in thick film benefit for their on-surface SMM behavior when compared with previously reported molecular magnetic deposits. Such films of dimers could be turned also into 
optoelectronic devices thanks to their unique luminescent properties. Overall, these dimers are an efficient platform to investigate a continuum between fundamental coordination chemistry studies, materials and devices. Last, they constitute excellent systems to investigate the challenging topic of magnetic or electric information addressing at the molecular scale.

\section{6) Acknowledgments}

All the collaborators involved in the reported studies are gratefully acknowledged. We thank the Swiss muon source S $\mu$ S, Paul Scherrer Institute, Villigen (Switzerland) for beamtime and the French GENCI/IDRIS-CINES center for high-performance computing resources. We thank INSA RENNES, CNRS (EMERGENCE@INC program), the Region Bretagne, Chinese Scholarship Council (CSC), the ERC Advanced Grant MolNanoMaS (proj. no. 267746), Italian MIUR through PRIN “Record” (20097X44S7) and FIRB "Nano-PlasMag” (RBFR10OAI0) projects for funding. KB Acknowledge the Institut Universitaire de France (IUF).

\section{7) Biographies}

Kevin Bernot was born in Saint-Malo, France. He received his Ph.D. in Chemistry in 2007 from both INSA-Rennes and the University of Florence (Italy). In 2008, he became an Associate Professor at INSA-Rennes. In 2017, he became Junior member of the Institut Universitaire de France (IUF). His research is focused on lanthanide coordination chemistry, molecular magnetism, and luminescence. 
Carole Daiguebonne was born in Thiers, France. She received her PhD. in Chemistry in 2000 from INSA-Rennes. She became an Assistant Professor at INSA-Rennes in 2002. Her research is focused on lanthanide coordination chemistry, including crystallogenesis and luminescence.

Guillaume Calvez was born in Morlaix, France. He received his Ph.D. in Chemistry in 2009 from INSA-Rennes. He became an Associate Professor at INSA-Rennes in 2011. His research is focused on lanthanide coordination chemistry, lanthanide-based polynuclear assemblies and luminescence.

Yan Suffren was born in Echirolles, France. He received his Ph.D. in Chemistry in 2010 from the University of Grenoble Alpes (France). He did two post-doctoral fellowship at the University of Montréal (Canada) and at the University of Geneva (Switzerland). In 2017, he became an Associate Professor at INSA-Rennes. His research is focused on lanthanide coordination chemistry, luminescence and spectroscopic characterizations.

Olivier Guillou was born in Guérande, France. He received his Ph.D. in 1993 from the University of Paris-Saclay. He became full professor at INSA Rennes in 2001. His main field of research is devoted to lanthanide-based coordination polymers with tunable luminescence properties.

\section{ASSOCIATED CONTENT}

\section{Supporting Information.}

Table of main geometric parameters of the dimers

Table of main magnetic figures of merit of the dimers 


\section{AUTHOR INFORMATION}

\section{Corresponding Author}

*(Kevin Bernot- Univ Rennes, INSA Rennes, CNRS, ISCR (Institut des Sciences Chimiques de

Rennes), UMR 6226, F- 35000 Rennes, France; Institut Universitaire de France (IUF), 75231

Paris, France; orcid.org/0000-0001-8337-6246; Email: Kevin.Bernot@insa-rennes.fr

\section{REFERENCES}

(1) Yi, X.; Bernot, K.; Pointillart, F.; Poneti, G.; Calvez, G.; Daiguebonne, C.; Guillou, O.; Sessoli, R.: A Luminescent and Sublimable Dy(III)-Based Single-Molecule Magnet. Chem.Eur. J. 2012, 18, 11379-11387.

(2) Huang, G.; Yi, X.; Jung, J.; Guillou, O.; Cador, O.; Pointillart, F.; Le Guennic, B.; Bernot, K.: Optimization of Magnetic Relaxation and Isotopic Enrichment in Dimeric DyIII Single-Molecule Magnets. Eur. J. Inorg. Chem. 2018, 326-332.

(3) Cimatti, I.; Yi, X.; Sessoli, R.; Puget, M.; Guennic, B. L.; Jung, J.; Guizouarn, T.; Magnani, A.; Bernot, K.; Mannini, M.: Chemical Tailoring of Single Molecule Magnet Behavior in Films of Dy(Iii) Dimers. Appl. Surf. Sci. 2018, 432, 7-14.

(4) Kiefl, E.; Mannini, M.; Bernot, K.; Yi, X.; Amato, A.; Leviant, T.; Magnani, A.; Prokscha, T.; Suter, A.; Sessoli, R.; Salman, Z.: Robust Magnetic Properties of a Sublimable Single-Molecule Magnet. ACS Nano 2016, 10, 5663-5669.

(5) Yi, X.; Shang, J.; Pan, L.; Tan, H.; Chen, B.; Liu, G.; Huang, G.; Bernot, K.; Guillou, O.; Li, R.-W.: Reversible Luminescence Modulation Upon an Electric Field on a Full Solid-State Device Based on Lanthanide Dimers. ACS Appl. Mater. Interfaces 2016, 8, 1555115556.

(6) Ribas, J.: Coordination Chemistry; Wiley-vch: Weinheim, 2008.

(7) Lawrance, G. A.: Introduction to Coordination Chemistry, 2009.

(8) Decurtins, S.; Pellaux, R.; Antorrena, G.; Palacio, F.: Multifunctional Coordination Compounds: Design and Properties. Coord. Chem. Rev. 1999, 192, 841-854.

(9) Tasiopoulos, A. J.; Vinslava, A.; Wernsdorfer, W.; Abboud, K. A.; Christou, G.: Giant Single-Molecule Magnets: A $\{\mathrm{Mn}-84\}$ Torus and Its Supramolecular Nanotubes. Angew. Chem.-Int. Edit. 2004, 43, 2117-2121.

(10) Whitehead, G. F. S.; Moro, F.; Timco, G. A.; Wernsdorfer, W.; Teat, S. J.; Winpenny, R. E. P.: A Ring of Rings and Other Multicomponent Assemblies of Cages. Angew. Chem.-Int. Ed. 2013, 52, 9932-9935.

(11) Mas-Balleste, R.; Gomez-Herrero, J.; Zamora, F.: One-Dimensional Coordination Polymers on Surfaces: Towards Single Molecule Devices. Chem. Soc. Rev. 2010, 39, 4220-4233. 
(12) Chen, C.-T.; Suslick, K. S.: One-Dimensional Coordination Polymers: Applications to Material Science. Coord. Chem. Rev. 1993, 128, 293-322.

(13) López-Cabrelles, J.; Mañas-Valero, S.; Vitórica-Yrezábal, I. J.; Bereciartua, P. J.; Rodríguez-VelamazáN, J. A.; Waerenborgh, J. C.; Vieira, B. J. C.; Davidovikj, D.; Steeneken, P. G.; Van Der Zant, H. S. J.; Mínguez Espallargas, G.; Coronado, E.: Isoreticular Two-Dimensional Magnetic Coordination Polymers Prepared through Pre-Synthetic Ligand Functionalization. Nat. Chem. 2018, 10, 1001-1007.

(14) Tran, M.; Kline, K.; Qin, Y.; Shen, Y.; Green, M. D.; Tongay, S.: 2d Coordination Polymers: Design Guidelines and Materials Perspective. Appl. Phys. Rev. 2019, 6, 041311.

(15) Yamabayashi, T.; Atzori, M.; Tesi, L.; Cosquer, G.; Santanni, F.; Boulon, M.-E.; Morra, E.; Benci, S.; Torre, R.; Chiesa, M.; Sorace, L.; Sessoli, R.; Yamashita, M.: Scaling up Electronic Spin Qubits into a Three-Dimensional Metal-Organic Framework. J. Am. Chem. Soc. 2018, 140, 12090-12101.

(16) Cui, Y.; Li, B.; He, H.; Zhou, W.; Chen, B.; Qian, G.: Metal-Organic Frameworks as Platforms for Functional Materials. Acc. Chem. Res. 2016, 49, 483-493.

(17) Coronado, E.: Molecular Magnetism: From Chemical Design to Spin Control in Molecules, Materials and Devices. Nature Reviews Materials 2019.

(18) Bünzli, J.-C. G.: Review: Lanthanide Coordination Chemistry: From Old Concepts to Coordination Polymers. J. Coord. Chem. 2014, 67, 3706-3733.

(19) Bunzli, J. C. G.: Benefiting from the Unique Properties of Lanthanide Ions. Acc. Chem. Res. 2006, 39, 53-61.

(20) Guillou, O.; Daiguebonne, C.; Calvez, G.; Bernot, K.: A Long Journey in Lanthanide Chemistry: From Fundamental Crystallogenesis Studies to Commercial Anticounterfeiting Taggants. Acc. Chem. Res. 2016, 49, 844-856.

(21) Moore, E. G.; Samuel, A. P. S.; Raymond, K. N.: From Antenna to Assay: Lessons Learned in Lanthanide Luminescence. Acc. Chem. Res. 2009, 42, 542-552.

(22) Timco, G. A.; Carretta, S.; Troiani, F.; Tuna, F.; Pritchard, R. J.; Muryn, C. A.; McInnes, E. J. L.; Ghirri, A.; Candini, A.; Santini, P.; Amoretti, G.; Affronte, M.; Winpenny, R. E. P.: Engineering the Coupling between Molecular Spin Qubits by Coordination Chemistry. Nat Nano 2009, 4, 173-178.

(23) Parker, D.; Suturina, E. A.; Kuprov, I.; Chilton, N. F.: How the Ligand Field in Lanthanide Coordination Complexes Determines Magnetic Susceptibility Anisotropy, Paramagnetic Nmr Shift, and Relaxation Behavior. Acc. Chem. Res. 2020.

(24) Benelli, C.; Gatteschi, D.: Introduction to Molecular Magnetism: From Transition Metals to Lanthanides; Wiley, 2015.

(25) Goodwin, C. A. P.; Ortu, F.; Reta, D.; Chilton, N. F.; Mills, D. P.: Molecular Magnetic Hysteresis at 60 Kelvin in Dysprosocenium. Nature 2017, 548, 439-442.

(26) Guo, F.-S.; Day, B. M.; Chen, Y.-C.; Tong, M.-L.; Mansikkamäki, A.; Layfield, R. A.: Magnetic Hysteresis up to 80 Kelvin in a Dysprosium Metallocene Single-Molecule Magnet. Science 2018, 362, 1400-1403.

(27) Meng, Y.-S.; Jiang, S.-D.; Wang, B.-W.; Gao, S.: Understanding the Magnetic Anisotropy toward Single-Ion Magnets. Acc. Chem. Res. 2016, 49, 2381-2389.

(28) Harriman, K. L. M.; Murugesu, M.: An Organolanthanide Building Block Approach to Single-Molecule Magnets. Acc. Chem. Res. 2016.

(29) Organometallic Magnets Springer International Publishing, 2019. 
(30) Gómez-Coca, S.; Aravena, D.; Morales, R.; Ruiz, E.: Large Magnetic Anisotropy in Mononuclear Metal Complexes. Coord. Chem. Rev. 2015, 289-290, 379-392.

(31) Woodruff, D. N.; Winpenny, R. E. P.; Layfield, R. A.: Lanthanide Single-Molecule Magnets. Chem. Rev. 2013, 113, 5110-5148.

(32) Cucinotta, G.; Perfetti, M.; Luzon, J.; Etienne, M.; Car, P.-E.; Caneschi, A.; Calvez, G.; Bernot, K.; Sessoli, R.: Magnetic Anisotropy in a Dysprosium/Dota Single-Molecule Magnet: Beyond Simple Magneto-Structural Correlations. Angew. Chem.-Int. Edit. 2012, 51, 1606-1610.

(33) Habib, F.; Murugesu, M.: Lessons Learned from Dinuclear Lanthanide NanoMagnets. Chem. Soc. Rev. 2013, 42, 3278-3288.

(34) Miralles, S. G.; Bedoya-Pinto, A.; Baldovi, J. J.; Canon-Mancisidor, W.; Prado, Y.; Prima-Garcia, H.; Gaita-Arino, A.; Minguez Espallargas, G.; Hueso, L. E.; Coronado, E.: Sublimable Chloroquinolinate Lanthanoid Single-Ion Magnets Deposited on Ferromagnetic Electrodes. Chem. Sci. 2018.

(35) Margheriti, L.; Chiappe, D.; Mannini, M.; Car, P. E.; Sainctavit, P.; Arrio, M. A.; de Mongeot, F. B.; Cezar, J. C.; Piras, F. M.; Magnani, A.; Otero, E.; Caneschi, A.; Sessoli, R.: XRay Detected Magnetic Hysteresis of Thermally Evaporated Terbium Double-Decker Oriented Films. Adv. Mater. 2010, 22, 5488-5493.

(36) Gao, C.; Yang, Q.; Wang, B.-W.; Wang, Z.-M.; Gao, S.: Evaporable Lanthanide Single-Ion Magnet. CrystEngComm 2016.

(37) Holmberg, R. J.; Murugesu, M.: Adhering Magnetic Molecules to Surfaces. J. Mater. Chem. C 2015, 3, 11986-11998.

(38) Eliseeva, S. V.; Ryazanov, M.; Gumy, F.; Troyanov, S. I.; Lepnev, L. S.; Bunzli, J. C. G.; Kuzmina, N. P.: Dimeric Complexes of Lanthanide(III) Hexafluoroacetylacetonates with 4Cyanopyridine N-Oxide: Synthesis, Crystal Structure, Magnetic and Photoluminescent Properties. Eur. J. Inorg. Chem. 2006, 4809-4820.

(39) Alvarez, S.; Alemany, P.; Casanova, D.; Cirera, J.; Llunell, M.; Avnir, D.: Shape Maps and Polyhedral Interconversion Paths in Transition Metal Chemistry. Coord. Chem. Rev. 2005, 249, 1693-1708.

(40) Yi, X.; Pointillart, F.; Le Guennic, B.; Jung, J.; Daiguebonne, C.; Calvez, G.; Guillou, O.; Bernot, K.: Rational Engineering of Dimeric Dy-Based Single-Molecule Magnets for Surface Grafting. Polyhedron 2019, 164, 41-47.

(41) Yi, X.; Calvez, G.; Daiguebonne, C.; Guillou, O.; Bernot, K.: Rational Organization of Lanthanide-Based SMM Dimers into Three-Dimensional Networks. Inorg. Chem. 2015, 54, 5213-5219.

(42) Koen, B.; K.A. Gschneidner, J. C. B.; Pecharsky, V. K.: Rare-Earth BetaDiketonates. In Handbook on the Physics and Chemistry of Rare Earths; Elsevier, 2005; Vol. Volume 35; pp 107-272.

(43) Bunzli, J.-C. G.: Lanthanide Luminescence for Biomedical Analyses and Imaging. Chem. Rev. 2010, 110, 2729-2755.

(44) Ungur, L.; Chibotaru, L. F.: Magnetic Anisotropy in the Excited States of Low Symmetry Lanthanide Complexes. Phys. Chem. Chem. Phys 2011, 13, 20086-20090.

(45) da Cunha, T. T.; Jung, J.; Boulon, M. E.; Campo, G.; Pointillart, F.; Pereira, C. L. M.; Le Guennic, B.; Cador, O.; Bernot, K.; Pineider, F.; Golhen, S.; Ouahab, L.: Magnetic Poles Determinations and Robustness of Memory Effect Upon Solubilization in a Dy-III-Based Single Ion Magnet. J. Am. Chem. Soc. 2013, 135, 16332-16335. 
(46) Llanos, L.; Aravena, D.: Relaxation Time Enhancement by Magnetic Dilution in Single-Molecule Magnets: An Ab Initio Study. J. Magn. Magn. Mater. 2019, 489, 165456.

(47) Habib, F.; Lin, P.-H.; Long, J.; Korobkov, I.; Wernsdorfer, W.; Murugesu, M.: The Use of Magnetic Dilution to Elucidate the Slow Magnetic Relaxation Effects of a Dy2 SingleMolecule Magnet. J. Am. Chem. Soc. 2011, 133, 8830-8833.

(48) Yi, X.; Bernot, K.; Cador, O.; Luzon, J.; Calvez, G.; Daiguebonne, C.; Guillou, O.: Influence of Ferromagnetic Connection of Ising-Type DyIII-Based Single Ion Magnets on Their Magnetic Slow Relaxation. Dalton Trans. 2013, 42, 6728-6731.

(49) Nguyen, T. N.; Wernsdorfer, W.; Shiddiq, M.; Abboud, K. A.; Hill, S.; Christou, G.: Supramolecular Aggregates of Single-Molecule Magnets: Exchange-Biased Quantum Tunneling of Magnetization in a Rectangular [Mn3]4 Tetramer. Chem. Sci. 2016.

(50) Lin, P.-H.; Yang, B.-Y.; Tsai, M.-H.; Chen, P.-C.; Huang, K.-F.; Lin, H.-H.; Lai, C.-H.: Manipulating Exchange Bias by Spin-Orbit Torque. Nat. Mater. 2019, 18, 335-341.

(51) Nava, A.; Rigamonti, L.; Zangrando, E.; Sessoli, R.; Wernsdorfer, W.; Cornia, A.: Redox-Controlled Exchange Bias in a Supramolecular Chain of Fe4 Single-Molecule Magnets. Angew. Chem.-Int. Ed. 2015, 54, 8777-8782.

(52) Chow, C. Y.; Bolvin, H.; Campbell, V. E.; Guillot, R.; Kampf, J. W.; Wernsdorfer, W.; Gendron, F.; Autschbach, J.; Pecoraro, V. L.; Mallah, T.: Assessing the Exchange Coupling in Binuclear Lanthanide(III) Complexes and the Slow Relaxation of the Magnetization in the Antiferromagnetically Coupled Dy2 Derivative. Chem. Sci. 2015, 6, 4148-4159.

(53) Han, T.; Giansiracusa, M. J.; Li, Z.-H.; Ding, Y.-S.; Chilton, N. F.; Winpenny, R. E. P.; Zheng, Y.-Z.: Exchange-Biasing in a Dinuclear Dysprosium(III) Single-Molecule Magnet with a Large Energy Barrier for Magnetization Reversal. Chem. Eur. J. 2020, 26, 6773-6777.

(54) Pointillart, F.; Bernot, K.; Golhen, S.; Le Guennic, B.; Guizouarn, T.; Ouahab, L.; Cador, O.: Magnetic Memory in an Isotopically Enriched and Magnetically Isolated Mononuclear Dysprosium Complex. Angew. Chem.-Int. Ed. 2015, 54, 1504-1507.

(55) Flores Gonzalez, J.; Pointillart, F.; Cador, O.: Hyperfine Coupling and Slow Magnetic Relaxation in Isotopically Enriched DyIII Mononuclear Single-Molecule Magnets. Inorg. Chem. Front. 2019, 6, 1081-1086.

(56) Kishi, Y.; Pointillart, F.; Lefeuvre, B.; Riobe, F.; Le Guennic, B.; Golhen, S.; Cador, O.; Maury, O.; Fujiwara, H.; Ouahab, L.: Isotopically Enriched Polymorphs of Dysprosium Single Molecule Magnets. Chem. Commun. 2017.

(57) Lanzilotto, V.; Malavolti, L.; Ninova, S.; Cimatti, I.; Poggini, L.; Cortigiani, B.; Mannini, M.; Totti, F.; Cornia, A.; Sessoli, R.: The Challenge of Thermal Deposition of Coordination Compounds: Insight into the Case of a Fe4 Single Molecule Magnet. Chem. Mat. 2016.

(58) Cornia, A.; Mannini, M.: Single-Molecule Magnets on Surfaces. In Molecular Nanomagnets and Related Phenomena; Springer Berlin Heidelberg, 2014; pp 1-38.

(59) Mannini, M.; Pineider, F.; Danieli, C.; Totti, F.; Sorace, L.; Sainctavit, P.; Arrio, M. A.; Otero, E.; Joly, L.; Cezar, J. C.; Cornia, A.; Sessoli, R.: Quantum Tunnelling of the Magnetization in a Monolayer of Oriented Single-Molecule Magnets. Nature 2010, 468, 417-421.

(60) Barra, A. L.; Caneschi, A.; Cornia, A.; Fabrizi de Biani, F.; Gatteschi, D.; Sangregorio, C.; Sessoli, R.; Sorace, L.: Single-Molecule Magnet Behavior of a Tetranuclear Iron(Iii) Complex. The Origin of Slow Magnetic Relaxation in Iron(III) Clusters. J. Am. Chem. Soc. 1999, 121, 5302-5310. 
(61) Ishikawa, N.; Sugita, M.; Ishikawa, T.; Koshihara, S.-y.; Kaizu, Y.: Lanthanide Double-Decker Complexes Functioning as Magnets at the Single-Molecular Level. J. Am. Chem. Soc. 2003, 125, 8694-8695.

(62) Wäckerlin, C.; Donati, F.; Singha, A.; Baltic, R.; Rusponi, S.; Diller, K.; Patthey, F.; Pivetta, M.; Lan, Y.; Klyatskaya, S.; Ruben, M.; Brune, H.; Dreiser, J.: Giant Hysteresis of Single-Molecule Magnets Adsorbed on a Nonmagnetic Insulator. Adv. Mater. 2016, 28, 51955199.

(63) Urdampilleta, M.; Klayatskaya, S.; Ruben, M.; Wernsdorfer, W.: Magnetic Interaction between a Radical Spin and a Single-Molecule Magnet in a Molecular Spin-Valve. ACS Nano 2015.

(64) Thiele, S.; Balestro, F.; Ballou, R.; Klyatskaya, S.; Ruben, M.; Wernsdorfer, W.: Electrically Driven Nuclear Spin Resonance in Single-Molecule Magnets. Science 2014, 344, $1135-1138$.

(65) Malavolti, L.; Mannini, M.; Car, P.-E.; Campo, G.; Pineider, F.; Sessoli, R.: Erratic Magnetic Hysteresis of Tbpc2 Molecular Nanomagnets. J. Mater. Chem. C 2013, 1, 2935-2942.

(66) Hofmann, A.; Salman, Z.; Mannini, M.; Amato, A.; Malavolti, L.; Morenzoni, E.; Prokscha, T.; Sessoli, R.; Suter, A.: Depth-Dependent Spin Dynamics in Thin Films of Tbpc2 Nanomagnets Explored by Low-Energy Implanted Muons. ACS Nano 2012, 6, 8390-8396.

(67) Bernot, K.: Molécules-Aimants. Techniques de l'Ingenieur 2019, re277.

(68) Binnemans, K.: Rare-Earth Beta-Diketonates. In Handbook on the Physics and Chemistry of Rare-Earths; K.A. Gschneider, J., Bünzli, J. C. G., Pecharsky, V. K., Eds.; Elsevier B.V.: Amsterdam, 2005; Vol. 35. 